\title{
On tracking control problem for polysolenoid motor model predictive approach
}

\author{
Nguyen Hong Quang ${ }^{1}$, Nguyen Phung Quang ${ }^{2}$, Do Trung Hai ${ }^{3}$, Nguyen Nhu Hien ${ }^{4}$ \\ 1,3,4 Department of Automation, Thai Nguyen University of Technology, Viet Nam \\ ${ }^{2}$ Institute for Control Engineering and Automation, Hanoi University of Science and Technology, Viet Nam
}

\begin{tabular}{l}
\hline Article Info \\
\hline Article history: \\
Received Jan 25, 2019 \\
Revised May 5, 2019 \\
Accepted Sep 27, 2019 \\
\hline Keywords: \\
Cascade control \\
Continuous control set model \\
predictive control \\
Min max model predictive \\
Permanent magnet linear \\
synchronous motor \\
Polysolenoid linear motor \\
\hline
\end{tabular}

\begin{abstract}
The Polysolenoid Linear Motor (PLM) have been playing a crucial role in many industrial aspects due to its functions, in which a straight motion is provided directly without mediate mechanical actuators. Recently, with several commons on mathematic model, some control methods for PLM based on Rotational Motor have been applied, but position, velocity and current constraints which are important in real systems have been ignored. In this paper, position tracking control problem for PLM was considered under state-independent disturbances via min-max model predictive control. The proposed controller forces tracking position errors converge to small region of origin and satisfies state including position, velocity and currents constraints. Further, a numerical simulation was implemented to validate the performance of the proposed controller.
\end{abstract}

Copyright $\odot 2020$ Institute of Advanced Engineering and Science. All rights reserved.

\section{Corresponding Author:}

Nguyen Hong Quang,

Department of Automation,

Thai Nguyen University of Technology,

666, 3/2 Street, Tich Luong ward, Thai Nguyen city, Viet Nam.

Email: quang.nguyenhong@ tnut.edu.vn

\section{INTRODUCTION}

Linear Motor transmission systems are widely applied to provide directed straight motions in which, mechanical actuators are eliminated, resulting in better performance of motion systems. Generally, Polysolenoid Linear Motor (PLM) has a durable structure, operations according to electromagnetic phenomenon with principles as shown in [1-12] and various applications such as CNC Lathe [13], sliding door [14]. Without the need of any gear box for motion transformation, the PLM system becomes sensitive due to external impacts such as frictional force, end - effect, changed load and non-sine of flux. These effects encounter both in the longitudinal and in the transversal direction, which is along with saturation in supplied voltage, make good control performance from the linear drive a difficult task.

There are several researches taking into account the position control of PLM in presence of external disturbances. The authors in [15] presented a control design method to regulate velocity based on PI - selftuning combining with appropriate estimation technique at slow velocity zone, but if load is changed, PI-self-tuning controller will be not efficient. In order to overcome changed load, model reference control method based on Lyapunov stability theory was employed in [16]. Additionally, the compensation approaches were proposed in research [17] on which, the frictional force were estimated by Lugrie and Stribeck friction model respectively. In [18], the advantage of that the sliding mode control applied in Linear Motor is that real position value tracks set point. However, the disadvantages of this method are finding sliding surface and chattering. In the view of nonlinear systems, the study in [19] apply linearization method to PLM system but this method is restricted by uncertain parameter and disturbances. It is clear that 
the previous researches do not mention position, velocity and currents constraints as well as impact of external disturbance which is important properties of the control systems.

\section{DYNAMIC MODEL} Figure 1.

Polysolenoid linear motor is constructed according to electromagnetic induction as shown in

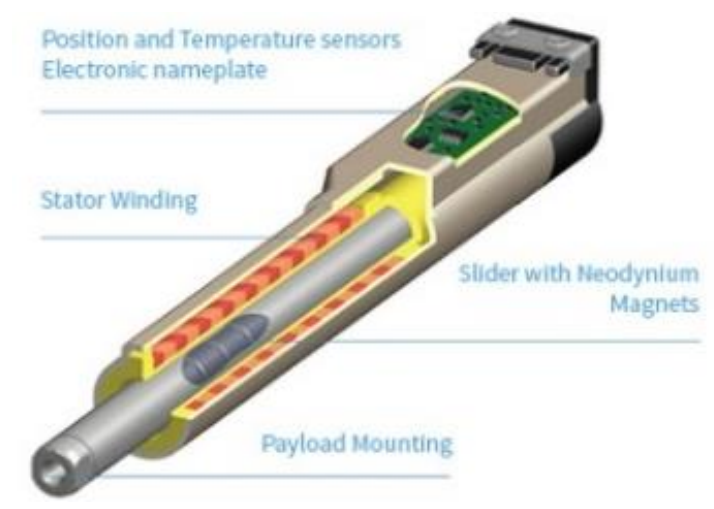

Figure 1. Composition of polysolenoid linear motor

Let us consider a dynamic model of PLM in [20-24]:

$$
\begin{aligned}
& \frac{d i_{s d}}{d t}=-\frac{R_{s}}{L_{s d}} i_{s d}+\left(\frac{2 \pi p}{\tau} v\right) \frac{L_{s q}}{L_{s d}} i_{s q}+\frac{u_{s d}}{L_{s d}}, \\
& \frac{d i_{s q}}{d t}=-\frac{R_{s}}{L_{s q}} i_{s q}-\left(\frac{2 \pi}{\tau} v\right) \frac{L_{s d}}{L_{s q}} i_{s d}-\left(\frac{2 \pi p}{p \tau} v\right) \frac{\psi_{p}}{L_{s q}}+\frac{u_{s q}}{L_{s q}}, \\
& \frac{d v}{d t}=\frac{2 \pi p}{\tau}\left(\psi_{p}+\left(L_{s d}-L_{s q}\right) i_{s d}\right) i_{s q}-\frac{1}{m} F_{l}, \\
& \frac{d x}{d t}=v .
\end{aligned}
$$

Where $i_{s d}, i_{s q}, v, x$ stand for current, velocity and position respectively. In addition, the constant parameter of PLM includes: $R_{s}, L_{s d}, L_{s q}, p, \tau, \psi_{p}, m$ as resistance, inductor, pole pair, pole step, flux and mass of rotor. The input voltage is presented as $u_{s d}, u_{s q}$ and $F_{c}$ is unmeasured external force. Suppose that, $F_{l}$ can be classify into finite set as $W=\left\{F_{1 c}, F_{2 c}, \ldots, F_{N c}\right\}$. It is worth to note that, the model (1) is similar to permanent magnet rotation synchronization motor model. Hence, let us assume that, $L_{s d}$ and $L_{s q}$ has the approximate similar values and the term $\left(L_{s d}-L_{s q}\right) i_{s d} i_{s q}$ can be ignored in the third equation of (1) that leads to linear relationship between current $i_{s q}$ and position-velocity.

\section{CONTROL DESIGN}

In this paper, let us separate dynamic model (1) into current subsystem and position subsystem. As aforementioned, position subsystem can be considered as a linear time invariant system under external disturbances and then, the position controller is designed with the aid of existed min-max model predictive control theory [25]. On the other hand, the cross-current compensation method between is used to transform first of two equation in (6) into linear form. Moreover, the current controller is based CCS model predictive control which can solve current constraint problem.

\subsection{Control of current subsystem}

By applying decoupling control law as follow:

$$
u_{s d}=-\left(\frac{2 \pi p}{\tau} v\right) L_{s q} i_{s q}+u_{1}, u_{s q}=\left(\frac{2 \pi p}{\tau} v\right) L_{s d} i_{s d}+\left(\frac{2 \pi p}{p \tau} v\right) \psi_{p}+u_{2}
$$


The current subsystem is transformed to linear system:

$$
\frac{d i_{s d}}{d t}=-\frac{R_{s}}{L_{s d}} i_{s d}+\frac{u_{1}}{L_{s d}}, \frac{d i_{s q}}{d t}=-\frac{R_{s}}{L_{s q}} i_{s q}+\frac{u_{2}}{L_{s q}}
$$

To design CCS-MPC in current closed loop, from (3), by using simple manner, let us obtain the discrete time predictive model as follows:

$$
i_{d q}^{e s t}(k+i+1)=\Phi i_{d q}^{e s t}(k+i)+H \bar{u}_{d q}(k+i), \forall i=0,1, \ldots, N_{c}-1
$$

Where $N_{c}$ is a prediction horizon, $i_{d q}^{e s t}(k+i+1)=\left[i_{d}^{e s t}(k+i+1), i_{q}^{e s t}(k+i+1)\right]^{T}$ is $(i+1)^{\text {th }}$. Estimated current vector on $d q$-coordinate and $i_{d q}^{e s t}(k)=i_{d q}(k)=\left[i_{d}(k), i_{q}(k)\right]^{T}$ at sample time $k$. The predictive control input vector is presented as $\bar{u}_{d q}(k+i)=\left[\bar{u}_{1}(k+i), \bar{u}_{2}(k+1)\right]^{T}, \bar{u}_{1}(k)=$ $u_{1}(k), \bar{u}_{2}(k)=u_{2}(k)$. With $T_{s}$ stand for sampling time, the state and input matrix $\Phi, H$ are:

$$
\Phi=\left[\begin{array}{cc}
e^{-\frac{R_{S} T_{S}}{L_{s d}}} & 0 \\
0 & e^{-\frac{R_{S} T_{S}}{L_{S q}}}
\end{array}\right], H=\left[\begin{array}{c}
\frac{1}{L_{s d}} \\
\frac{1}{L_{s q}}
\end{array}\right]
$$

The control task is to find the sequence of control input vector $\bar{u}_{d q}(k), \bar{u}_{d q}(k+1), \ldots \ldots, \bar{u}_{d q}$ $(k+N-1)$, which minimize the following cost function:

$$
J=\sum_{i=1}^{N}\left(i_{d q}^{r e f}-i_{d q}^{e s t}(k+i+1)\right)^{T} Q_{1}\left(i_{d q}^{r e f}-i_{d q}^{e s t}(k+i \mid k)\right)
$$

Where $Q_{1}=\left[\lambda_{d} 0 ; 01\right]$ is positive matrix, $i_{q}^{r e f}$ is reference input vector from position controller which is present in the next section, $\lambda_{d}$ represent proportional ratio between $d$-current error $\left|i_{d}^{r e f}-i_{d}\right|$ and $q$-current error $\left|i_{q}^{r e f}-i_{q}\right|$. In order to simplify the optimization (6), let us assume that the reference input vector $i_{q}^{r e f}$ is constant in the prediction horizon time. The assumption is common in practical experiment due to the fact that current loop transition response is considerably faster than its position loop. Moreover, the predictive control input normally subjected to the linear constraint $A_{c o n} \bar{u}_{d q}(k+i)<B_{\text {con }}$. The current controller frequently operate in small sample $T_{s}$, thereby the one step horizon $N_{c}=1$ was take into account for the control design. And then, by selecting optimal variable $\bar{u}_{d q}(k)=u_{d q}(k)$, the minimization (6) can be rewritten as:

$$
\begin{aligned}
& \min _{\bar{u}_{d q}(k)} J=\bar{u}_{d q}(k)^{T}\left(H^{T} Q H\right) \bar{u}_{d q}(k)+2\left(\Phi i_{d q}(k)-i_{d q}^{r e f}\right)^{T} Q_{2} H \bar{u}_{d q}(k)+ \\
& \text { Cs.t. } A_{\text {con }} \bar{u}_{d q}(k)<B_{\text {con }}, \forall k=1,2, \ldots, N-1
\end{aligned}
$$

\subsection{Control of position subsystem}

The dynamic of position subsystem is significantly slower than current subsystems. Hence, in the control design of position, we assumed that the desired current equals to actual current. By setting $i_{s q}=u+m \tau\left(2 \pi p \psi_{p}\right)^{-1} \ddot{x}_{r}$, the last two equation of (1) can be rewritten as discrete state space model of tracking errors as:

$$
\begin{aligned}
& z_{k+1}=A_{d} z_{k}+B_{d} u_{k}+D_{d} d_{k}, \\
& y_{k}=C z_{k} .
\end{aligned}
$$

Where: $e_{x}=x-x_{r}, e_{v}=v-v_{r}, z=\left[e_{x}, e_{v}\right]^{T}, d_{k}=F_{l}\left(k T_{w}\right), u_{k}=i_{s q}(k)$

$$
A_{d}=\left[\begin{array}{cc}
1 & T_{w} \\
0 & 1
\end{array}\right], B_{d}=\left[\begin{array}{c}
\frac{T_{w}^{2}}{2} \\
2 \pi p(m \tau)^{-1} T_{v}
\end{array}\right], D_{d}=\left[\begin{array}{c}
\frac{T_{w}^{2}}{2} \\
-m^{-1} T_{v}
\end{array}\right], C=[1,0],
$$

The control input $u_{k}$ is designed to force error vector $z_{k}$ converge to small region centered at origin. Moreover, $z_{k}, u_{k}$ satisfies the following constraints:

$$
z_{k} \in Z, u_{k} \in U \text { andz }_{k} \rightarrow Z_{0} \in Z \text {, }
$$


where $Z_{0} \triangleq\left\{\left(z_{1}, z_{2}\right) \in \mathbb{R}^{2} \mid e 12_{0 v \max } 0\right.$ vmin $\left._{0 \operatorname{mmax}_{0 x \min }}\right\}$

$Z_{0} \in Z \triangleq\left\{\left(z_{1}, z_{2}\right) \in \mathbb{R}^{2} \mid e 12_{\text {vmax }} v_{\min } \max _{x \min }\right\}$

$U \triangleq\left(U_{\min }^{\max } \in \mathbb{R}.\right)$

To achieve control objective (9), min-max model predictive control proposed in [6] was applied. The operation of the position controller is devided into two modes: an "inner" and an "outer" controller. The inner controller is actived when the state is in the robust control invariant set $Z_{0}$, and its role is to keep the error state in $Z_{0}$ under external disturbance $d_{k}$. The inner controller is linear feedback $u_{k}=K z_{k}$ and it is important in the construction of the control robust invariant set $Z_{0}$ which is selected based on $\left(A_{d}+B_{d} K\right)^{S}=0$, sis positive integer number. To be specific, let us select $Z_{0}=\sum_{1}^{S}\left(A_{d}+\right.$ $\left.B_{d} K\right)^{s} D_{d} W$ where, $W$ is disturbance set.

The outer controller works when the error state is outside the invariant set $Z_{0}$ and steers the system state to the invariant set. For the outer controller, we use min-max model predictive control, and consider a fixed horizon formulation. In this section, the selected quadratic cost function as:

$$
\begin{aligned}
& L(\underline{z}, \underline{u}, \underline{d})=\sum_{i=0}^{N_{W}-1}\left(z_{k+i}^{T} Q z_{k+i}+u_{k+i}^{T} R u_{k+i}\right), \\
& Q \geq 0, R>0 .
\end{aligned}
$$

Where $\_z=\left[z_{k}, z_{k+1}, \ldots, z_{k+N-1}\right]^{T}, \underline{u}=\left[u_{k}, u_{k+1}, \ldots, u_{k+N-1}\right]^{T}, \underline{d}=\left[d_{k+1}, d_{k+2}, \ldots, d_{k+N-1}\right]^{T}$.

Herein, sequence vectoruis chosen to minimize cost function (10) in the worst case where, dis maximum point of (10). The following algorithm summarize the operation of position controller.

Algorithm 1: (Position Controller)

Data: $\mathbf{z}_{k}$

If $z_{k} \in Z_{0}$, set $u_{k}=K z_{k}$. Otherwise, find the solution of (11) and set $\mathbf{u}_{k}$ to the first control in the optimal sequence $\underline{u}$.

\section{NUMERICAL SIMULATION}

In this section, we simulate the position tracking of whole system under state, input constraint and external disturbance in following table. We use the same current controller and two different prediction horizons of position controller to compare quality of each controller. The parameter of polysolenoid linear motor and controller show in Table 1. As can be seen in Figure 2, both position and velocity error stay in state constraints region and converges to small ball centered at origin. The current is satisfying input constraint under time varying external forces.

Table 1. The parameter of polysolenoid linear motor and controller

\begin{tabular}{cccc}
\hline Parameter & Value & Controller parameter & Value \\
\hline Pole pair & 1 & exxmin $_{\text {0xmax }}$ & $0.2(\mathrm{~mm})$ \\
Pole step & $20(\mathrm{~mm})$ & evomin $_{\text {vimax }}$ & $1.5(\mathrm{~m} / \mathrm{s})$ \\
Rotor mass & $0.17(\mathrm{~kg})$ & $\lambda_{d}$ & 10 \\
Phase coil Resistance & $10.3(\Omega)$ & $\mathrm{K}$ & {$[-300-5]$} \\
d-axis inductance & $1.4(\mathrm{mH})$ & $\mathrm{U}$ & {$[-50,50]$} \\
q-axis inductance & $1.4(\mathrm{mH})$ & & \\
Flux & $0.035(\mathrm{~Wb})$ & & \\
\hline
\end{tabular}
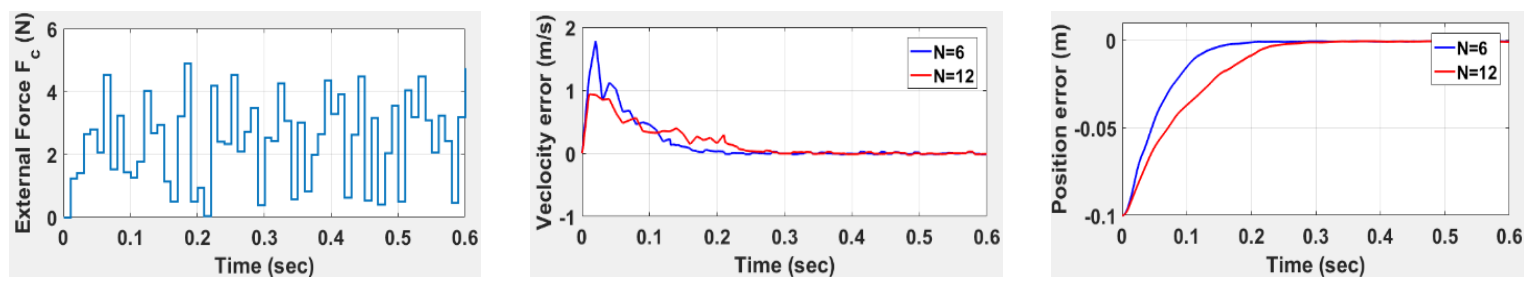

Figure 2. The performance of proposed controller (continue) 

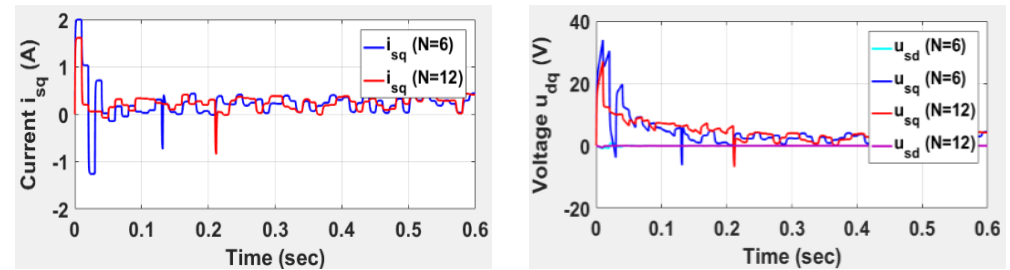

Figure 2. The performance of proposed controller

\section{CONCLUSION}

We also illustrated the impact of prediction horizon $N_{w}$ on performance of the system. If $N_{w}$ is small, the dynamic closed loop system is fast, settling time is small but input constraints may not hold. We have to choose $\mathrm{N}$ is sufficiently large to satisfy constraints. The proposed two cascade loops based on MPC with suficiently small prediction horizon $\left(N_{c}\right)$ of the current loop to reduce calculation load of microprocessors due to small sampling time of the current loop. When considering the current response is ideal, the system performance is totally depending on min-max MPC of the outer loop.

\section{ACKNOWLEDGEMENTS} Technology.

This research was supported by Research Foundation funded by Thai Nguyen University of

\section{REFERENCES}

[1] Ng. Ph. Quang, J. A. Dittrich, Vector Control of Three-Phase AC Machines - System Development in the Practice, 2nd Edition, Springer Berlin Heidelberg, 2008.

[2] Daniel Ausderau, "Polysolenoid - Linearantrieb mit genutetem Stator," Zurich. PhD Thessis, 2004.

[3] Danh Huy Nguyen, et al., "Nonlinear Control of an Active Magnetic Bearing with Output Contraint," International Journal of Electrical and Computer Engineering (IJECE), vol. 8(5), pp. 3666-3677, 2018.

[4] H. Chen, K. Liang, R. Nie, X. Liu, "Three-Dimensional Electromagnetic Analysis of Tubular Permanent Magnet Linear Launcher", Applied Superconductivity IEEE Transactions on, vol. 28, no. 3, pp. 1-8, 2018.

[5] Hossein Torkaman, Aghil Ghaheri, Ali Keyhani, "Axial flux switched reluctance machines: a comprehensive review of design and topologies", Electric Power Applications IET, vol. 13, no. 3, pp. 310-321, 2019.

[6] Hao Chen, Yiming Zhan, Rui Nie, Shuyan Zhao, "Multiobjective Optimization Design of Tubular Permanent Magnet Linear Launcher", Plasma Science IEEE Transactions on, vol. 47, no. 5, pp. 2486-2492, 2019.

[7] Jordi Garcia-Amorós, "Linear Hybrid Reluctance Motor with High Density Force", Energies, vol. 11, pp. 2805, 2018.

[8] B. Tomczuk, G. Schroder, A. Waindok, "Finite Element Analysis of the Magnetic Field and Electromechanical Parameters Calculation for a Slotted Permanent Magnet Tubular Linear Motor", IEEE Trans on magnetic, vol. 43, no. 7, pp. 3229-3236, 2007.

[9] I. I. Abdalla, T. Ibrahim and N. M. Nor, "Analysis of Tubular Linear Motors for Different Shapes of Magnets," in IEEE Access, vol. 6, pp. 10297-10310, 2018. doi: 10.1109/ACCESS.2017.2775863

[10] H. R. Esfahanian, S. Hasanzadeh and M. Heydari, "Performance Analysis and Force Components Improvement of an Tubular Linear Induction Motor Used in a Novel Magnetic Train by 3-D FEM," Electrical Engineering (ICEE), Iranian Conference on, Mashhad, 2018, pp. 1368-1372. doi: 10.1109/ICEE.2018.8472417

[11] X. Z. Huang, J. Li, Q. Tan, C. M. Zhang and L. Li, "Design Principles of a Phase-Shift Modular Slotless Tubular Permanent Magnet Linear Synchronous Motor With Three Sectional Primaries and Analysis of Its Detent Force," in IEEE Transactions on Industrial Electronics, vol. 65, no. 12, pp. 9346-9355, Dec. 2018. doi: 10.1109/TIE.2018.2813992

[12] V. Tiunov, "Practical Application and Methods of Calculation for Linear Induction Motors," 2018 International Multi-Conference on Industrial Engineering and Modern Technologies (FarEastCon), Vladivostok, 2018, pp. 1-6. doi: 10.1109/FarEastCon.2018.8602929

[13] Yang Zeqing, Liu Libing, Wangzuojie, Chen Yingshu, Xiao Quanyang, "Static and Dynamic Characteristic Simulation of Feed System Driven by Linear Motor in High Speed Computer Numerical Control Lathe," TELKOMNIKA (Telecommunication, Computing, Electronics and Control), vol. 11(7), pp. 3673-3683, 2013.

[14] Aymen Lachheb, Jalel Khediri, Lilia El Amraoui, "Performances Analysis of a Linear Motor for Sliding Door Application," International Journal of Power Electronics and Drive System (IJPEDS), vol. 8(3), pp. 1139-1146, 2017.

[15] Jul-Ki Seok, Jong-Kun Lee, Dong-Choon Lee, "Sensorless Speed Control of Nonsalient Permanent Magnet Synchronous Motor Using Rotor-Position-Tracking PI Controller," IEEE Transactions on IndustrialElectronics, vol. 53(2), pp. 399-405, 2006. 
[16] Yuan - Rui Chen, Jie Wu, Nobert Cheung, "Lyapunov's Stability Theory - Based Model Reference Adaptive Control for Permanent Magnet Linear Motor Drives," Proc of Power Electronics Systems and Application, pp. $260-266,2004$.

[17] C. Huang, Li - Chen Fu, "Adaptive Backstepping Speed/Position Control with Friction Compensation for Linear Induction Motor," Prod. of the 41st IEEE Conference on Decision and Control, USA, pp. 474 - 479, 2002

[18] G. Tapia, A. Tapia, "Sliding - Mode Control for Linear Permanent - Magnet motor Position Tracking," Proceeding of the IFAC World Congress, 2007.

[19] Quang H. Nguyen, et. al., "Design an Exact Linearization Controller for Permanent Stimulation Synchronous Linear Motor Polysolenoid," SSRG International Journal of Electrical and Electronics Engineering, vol. 4(1), 2017.

[20] Quang. N. H, et al., "Flatness Based Control Structure for Polysolenoid Permanent Stimulation Linear Motors," SSRG International Journal of Electrical and Electronics Engineering, vol. 3(12), pp. 31-37, 2016.

[21] Quang N. H., et al., "Multi Parametric Programming based Model Predictive Control for tracking Control of Polysolenoid Linear Motor," Special issue on Measurement, Control and Automation, vol. 19, pp. 31-37, 2017.

[22] Nguyen Hong Quang, et al., "Min Max Model Predictive Control for Polysolenoid Linear Motor," International Journal of Power Electronics and Drive System (IJPEDS), vol. 9(3), pp. 1666-1675, 2018.

[23] Nguyen Hong Quang., et al., "Multi parametric model predictive control based on laguerre model for permanent magnet linear synchronous motors," International Journal of Electrical and Computer Engineering (IJECE), vol. 9(2), pp. 1067-1077, 2019.

[24] Dao Phuong Nam, et al., "Multi Parametric Programming and Exact Linearization based Model Predictive Control of a Permanent Magnet Linear Synchronous Motor," International Conference on System Science and Engineering (ICSSE), pp. 743-747, 2017.

[25] P. O. M. Scokaert, D. Q. Mayne, "Min-Max Feedback Model Predictive Control for Constrained Linear Systems," IEEE Transactions On Automatic Control, vol. 43(8), 1998.

\section{BIOGRAPHIES OF AUTHORS}
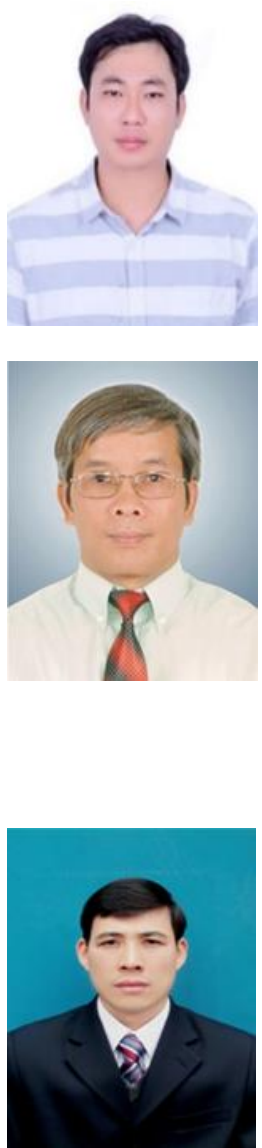

Hong Quang Nguyen received the B.S degree in electrical engineering from Thai Nguyen University of technology (TNUT), Vietnam, 2007, the Master's degree in control engineering and automation from Hanoi University of Science and Technology (HUST), Viet Nam, 2012 and Ph.D from Thai Nguyen University of technology (TNUT), Vietnam, 2019. He is current working as a lecturer at Department of Industrial Automation, Faculty of Electrical Engineering, Thai Nguyen University of Technology(TNUT). His Research Interests include Electrical Drive Systems, Adaptive Dynamic Programming Control, Robust Nonlinear Model Predictive Control, Motion Control, Control System and its Applications, Mechachonics.

Nguyen Phung Quang received his Dipl.-Ing. (Uni.), Dr.-Ing. and Dr.-Ing. habil. degrees from TU Dresden, Germany in 1975, 1991 and 1994 respectively. Prior to his return to Vietnam, he had worked in Germany industry for many years, contributed to create inverters REFU 402 Vectovar, RD500 (REFU Elektronik); Simovert 6SE42, Master Drive MC (Siemens). From 1996 to 1998, he served as lecturer of TU Dresden where he was conferred as Privatdozent in 1997. He joined Hanoi University of Science and Technology in 1999, as lecturer up to now. He is currently a professor of HUST and honorary professor of TU Dresden. He was author/co-author of more than 170 journal and conference papers; 8 books with three among them was written in German and one in English entitled "Vector Control of Three-Phase AC Machines - System Development in the Practice" published by Springer in 2008, and 2nd edition in June 2015. . His Research Interests are Electrical Drive Systems, Motion Control, Robotic Control, Vector Control of Electrical Machines, Wind and Solar Power Systems, Digital Control Systems, Modeling and Simulation.

Do Trung Hai born in 1974, received the PhD. degree in Automation from Ha Noi University of Technology and Science in 2008 and working in Thai Nguyen University of Technolgy now. His research interests include motion control, modern control theory 


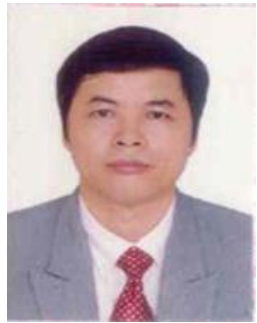

Nguyen Nhu Hien received the B.S. degree in electrical engineering from Bac Thai University of Mechanics and Electrics (former name of Thai Nguyen University of Technology) in 1976, the M.S degree and the PhD degree in automation and control from Ha Noi University of Science and Technology in 1997 and 2002 respectively. He is currently a Associate Professor with Automation Division, Faculty of Electrical Engineering, Thai Nguyen University of Technology. His current research interests include advance control of multi-axis drive system, control for multivariable processes and renewable energy systems. 